\title{
DÜBLIN
}

Technological University Dublin

ARROW@TU Dublin

2014-06-19

\section{Work in Progress: Online Resource Platform for Mathematics Education}

\author{
Marisa Llorens \\ Technological University Dublin, marisa.llorens@tudublin.ie \\ Edmund Nevin \\ Technological University Dublin, edmund.nevin@tudublin.ie \\ Eileen Mageean \\ Technological University Dublin, eileen.mageean@tudublin.ie
}

Follow this and additional works at: https://arrow.tudublin.ie/engschcivcon

Part of the Educational Methods Commons, and the Mathematics Commons

\section{Recommended Citation \\ Llorens-Salvador, M., Nevin, E., and Mageean, E., 2014. Work in Progress: Online Resource Platform for Mathematics Education. 9th Iberian Conference on Information Systems \& Technologies (CISTI'2014). Barcelona, Spain. 18-21 June 2014.}

This Conference Paper is brought to you for free and open access by the School of Civil and Structural Engineering at ARROW@TU Dublin. It has been accepted for inclusion in Conference papers by an authorized administrator of ARROW@TU Dublin. For more information, please contact arrow.admin@tudublin.ie, aisling.coyne@tudublin.ie,gerard.connolly@tudublin.ie.

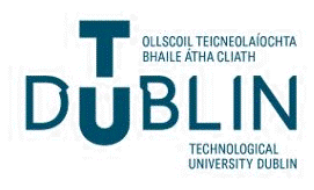




\title{
Work in Progress: Online Resource Platform for Mathematics Education
}

\author{
Marisa Llorens ${ }^{1}$, Edmund Nevin ${ }^{2}$ and Eileen Mageean ${ }^{3}$ \\ ${ }^{1,3}$ School of Multi-Disciplinary Technologies, ${ }^{2}$ School of Civil \& Structural Engineering \\ Dublin Institute of Technology \\ Ireland \\ ${ }^{1}$ marisa.1lorens@dit.ie, ${ }^{2}$ edmund.nevin@dit.ie, ${ }^{3}$ eileen.mageean@dit.ie
}

\begin{abstract}
Mathematics is intrinsic to engineering and as such plays an integral role in the education of engineers. New challenges are being faced in higher education particularly in the areas of student motivation, engagement and attainment. As a result mathematics is often the focus of engineering education research. Traditional methods of delivery such as lectures and tutorials need to evolve to counter these challenges with new pedagogical approaches explored including the use of new technologies. Today's students are immersed in an increasingly technological world and are willing to adapt to new technological advances. This paper describes a study being undertaken in the College of Engineering and the Built Environment at the Dublin Institute of Technology to develop and explore the use of a Sharable Content Object Reference Model (SCORM) that integrates a web-based platform for the study of mathematics as part of an active learning constructivist setting. Students will utilise graphics tablets to create online content consisting of solutions to mathematical problems which will then be used by other students to reinforce core concepts. The platform will provide active support to engineering students especially those in their first year of study and mature students returning to education. It is expected that early use of the platform will help identify areas of weakness and provide the self-learning environment required for students to become more proficient in those areas. By challenging the student to demonstrate an active engagement in their learning and by encouraging the meaningful use of technology in the classroom, an improvement in the quality of learning that students experience should be realised.
\end{abstract}

Keywords-engineering mathematics; active learning; student engagement; student learning experience; graphics tablets

\section{INTRODUCTION}

The central role played by mathematics in the education of engineers faces many challenges. A decline in the basic mathematical skills and the level of preparation on entry to higher education are two reasons that have been put forward in the past as possible contributors [1]. Consequently, many students taking engineering programmes lack the necessary maths skills required to succeed in these programmes [2]. A number of further possible contributing factors include: a lowering of entry requirements; diversity of the student cohort and; difficulty in teaching large classes without adequate resources. The role of the educator must adapt to these challenges and a more comprehensive learning support system needs to be explored and implemented.
Students with weak mathematical skills generally struggle more to achieve the learning outcomes of technical modules. In order to ensure these are met and to stimulate a deeper learning experience, a pedagogical shift from one of student passivity to one where students become agents in their own learning is required. The traditional hierarchical approach to learning, described by Bovill [3], which sees the "expert tutor" positioned in front of "subordinate learners", is under threat as the needs and expectations of the learner change.

The active learning approach shifts the focus from content delivery by the lecturer to active engagement of the material by the student. It consists of a number of key elements [4]: active responsibility for learning on the students' part; proactive management of the learning experience; independent knowledge construction and; lecturers as facilitators. The primary aim of an active learning environment is to "maintain and encourage students' motivation to learn, to inspire confidence and make them ambitious during their studies" [5]. Rather than the student passively sitting in a lecture/tutorial they are actively engaged in activity and thus actively learning. This reflects the views of Prince [6] to whom active learning "...refers to activities that are introduced into the classroom. The core elements of activity are student activity and engagement in the learning process."

Technological advances mean that communication methods have changed, almost unrecognisably, in the past 10 to 15 years. In order to make subject content appropriate to students' learning and communication styles it is necessary for the lecturer to communicate with a similar set of tools [6]. When the present cohort of third level students first entered the education system, many of the technologies available today either did not exist or were not readily available. The students' ability to quickly adapt to the introduction of new technologies and the greater availability of technology present new opportunities for educators to include the student as co-creator of course content.

The use of technology as a teaching and learning tool is widely documented in research literature. In one example, to promote a deeper learning experience McCartan et al. [7] looked at the effect of an active and interactive learning approach to the teaching of engineering mathematics. The move towards a more student-centred approach affords the student greater responsibility for their learning and provides 
them with a sense of ownership thereby enhancing the student learning experience. This shift involves the student becoming "agents in the process of transformative learning" [8] which can be triggered by critical reflection when positive adjustments are made to prior learning [9].

This paper outlines a study undertaken to create an on-line platform of resources that will allow first year engineering students to consolidate and reinforce the core mathematical skills required to succeed in their engineering studies. By including the student as co-creator of course content a greater sense of empowerment will be achieved. The use of technology to enhance the first year learning experience and as a means of increasing student motivation, engagement and attainment is explored.

\section{METHODOLOGY}

The active learning approach used for this study is built on a number of key principles: The students' will demonstrate active performance in their studies; Core mathematical concepts which are proving difficult to understand will receive greater focus; Student activity will be increased by encouraging participation and; The student will be encouraged to give feedback at regular intervals.

The online platform will consist of a set of quizzes and applications for the study of engineering mathematics. The quizzes will adapt and change depending on the answers provided by the student and will include appropriate video feedback for incorrect answers before the student is permitted to progress to the next question.

Based on the idea that teaching a concept is the best way to learn that concept, the students will be the active actors in the platform as they will create the videos that provide feedback to the other users of the platform. Pre and post reflection will be encouraged as students prepare and view the results of their videos. This active learning and constructivist approach will provide an environment of achievement and ownership that will empower students of all levels to benefit maximally from the learning experience. The platform is intended to reinforce core concepts and provide students with a multimedia tool created mainly by students for the benefit of other students.

This study can be broken down into two distinct parts. The first part involves the student creating solutions to mathematical problems. Also included in the solution will be commentary on where common mistakes are made. The second part involves the creation of the online content which will consist of the quizzes incorporating video feedback.

\section{A. Creating solutions to mathematical problems:}

To facilitate the use of the platform in standard classrooms and to aid the creation of the feedback videos, graphics tablets will be made available to the students. The graphics tablets chosen for this study are Wacom ${ }^{\circledR}$ Intuos Pen \& Touch Medium as illustrated in Fig. 1. The use of this type of technology is common in areas such as architecture and product design but as yet has not made an impact as a teaching tool for mathematics in higher education. Unlike Carillo et al. [10] who document the use of graphics tablets in the delivery of lecturer created course content, here we will document the student use of graphics tablets to create the content.

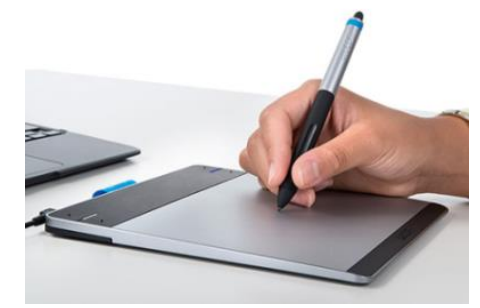

Figure 1. The Wacom ${ }^{\circledR}$ graphics tablet used for the study

The feedback videos will be created by the student, during tutorial sessions, under the guidance of the lecturer. In preparation the student will carry out a number of steps: firstly, subject content from various sources will be synthesised; next, a script of the narrative to be used will be written (see Fig. 2); lastly, the final version of the script will be rehearsed prior to the creation of the video. Each of the steps serves the purpose of repeatedly exposing and reinforcing the subject matter for the student. In this context students will determine their own learning by exploring knowledge in an active learning setting rather than receiving it in a passive lecture environment.

\section{B. Creating the online content:}

The two main components used for creating the online content are the SCORM package and the Learning Management System (LMS). The LMS used in this study is Webcourses ${ }^{\circledR}$. A SCORM is a collection of technical standards for e-learning software products. It provides specifications for standardising the reusability and interoperability of learning content. The main components of a SCORM are the Shareable Content Objects (SCOs). Fig. 3 illustrates how the online learning content and the LMS communicate with each other.

Once the individual SCOs are created they are assembled into a package with delivery instructions. The SCOs will consist of quizzes and tutorial videos. The LMS then loads the SCOs and delivers them according to instructions. The LMS will keep statistics of students' usage of the platform.

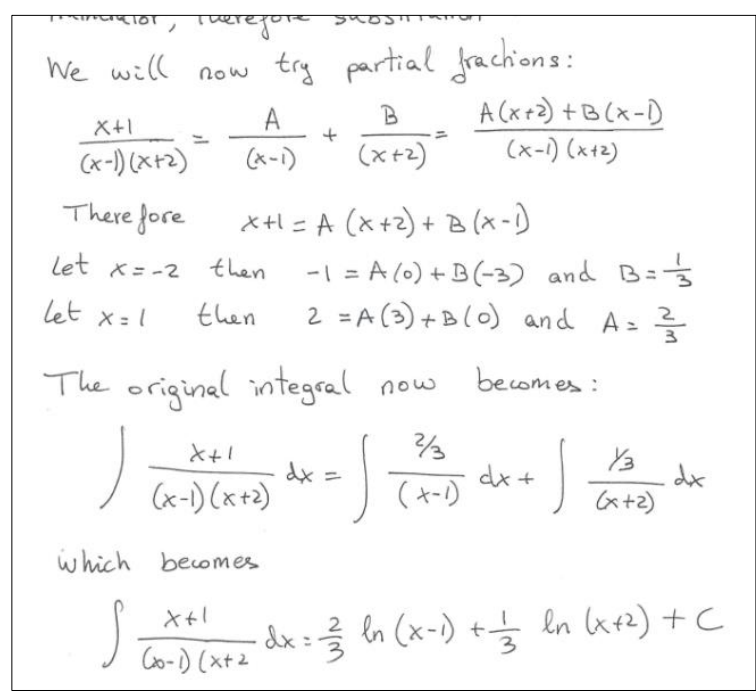

Figure 2. Extract from of a typical script prepared by the student. 


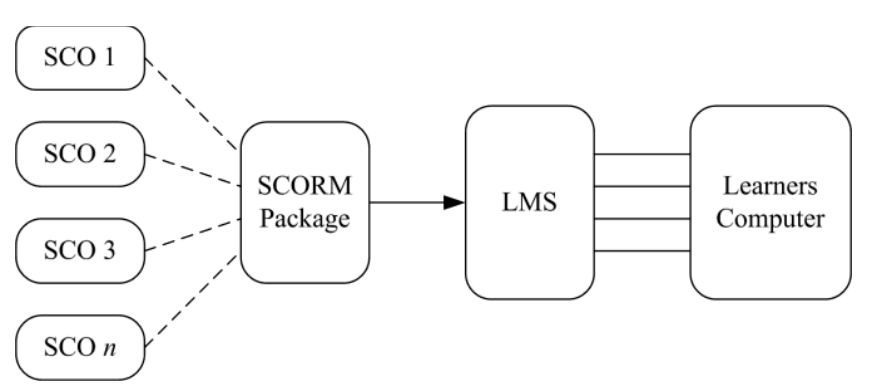

Figure 3. SCORM and LMS communication.

The feedback videos together with the quiz questions and the instructions form the final SCORM package that will be integrated into the LMS. The instructions will contain details on the order and number of questions to be answered by the student. These instructions will manage the different paths to be taken depending on the answers provided by the student whilst also allowing video to be embedded in the quiz. Tailored video feedback can be provided when a student answers a question incorrectly and before they move to the next question with the next question being of a similar level and on the same topic as the previous question that was incorrectly answered.

Fig. 4 illustrates the process employed. Questions will be accessed in ascending order of difficulty starting with the easiest. These questions lie along the main question path (MQP). When a question is answered incorrectly the student cannot proceed and is directed to the feedback/reinforcement path (FRP). Here they will be able to view videos to help reinforce the concept being examined by the incorrectly answered question. On successful completion the student returns to the MQP and proceeds to the next question. A sample question from the MQP and its connected feedback path question are displayed in Fig. 5 and Fig. 6 respectively.

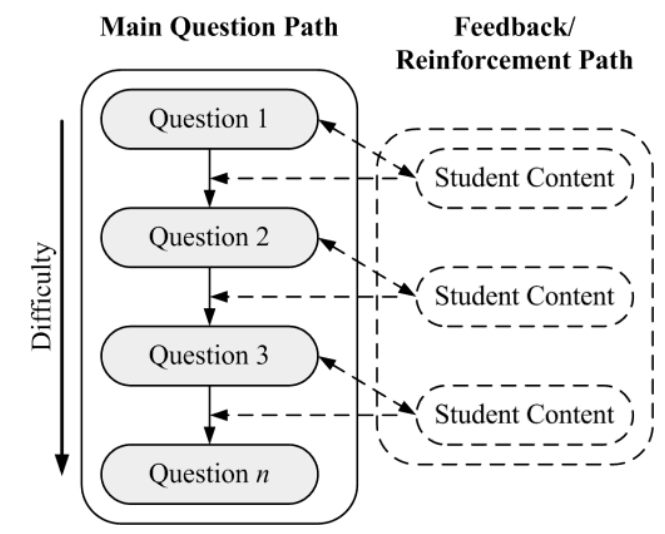

Figure 4. Main question and feedback paths.

\begin{tabular}{|l|l|}
\hline \multicolumn{2}{|c|}{$\begin{array}{c}\text { Question (Main Question Path): } \\
\text { Integrate: } \int \frac{x+3}{(x+1)(x+2)} d x\end{array}$} \\
\hline \multirow{3}{*}{ Possible } & (a) $2 \ln (x+2)+\ln (x+1)+C$ \\
solutions & (b) $2 \ln (x+1)-\ln (x+2)+C$ \\
& (c) $\frac{1}{2} \ln (x+1)-2 \ln (x+2)+C$ \\
\hline
\end{tabular}

Figure 5. Sample quiz question from MQP.

\begin{tabular}{|l|l|}
\hline \multicolumn{2}{|c|}{$\begin{array}{l}\text { Question (Feedback/Reinforcement Path): } \\
\text { Integrate: } \int \frac{\boldsymbol{x + 1}}{(\boldsymbol{x}-1)(\boldsymbol{x}+\mathbf{2})} \boldsymbol{d x}\end{array}$} \\
\begin{tabular}{ll} 
Possible & (a) $\ln (x-1)+\ln (x+2)+C$ \\
solutions & (b) $-1 \ln (x-1)+2 \ln (x+2)+C$ \\
& (c) $\frac{2}{3} \ln (x-1)+\frac{1}{3} \ln (x+2)+C$ \\
\hline
\end{tabular}
\end{tabular}

Figure 6. Sample quiz question from FRP.

\section{EXPECTED OUTCOMES}

The platform will develop the students' mathematical capability through the strengthening of core competencies. Through self-determined and student-centred learning an environment of achievement and ownership will develop. Mathematics assessments will become more of a learning experience than a measure of attainment. Students will become empowered by participation in an active learning environment and will be less likely to rely on rote learning and regurgitation which characterize a shallow understanding of concepts. The role of the student as a valuable resource in teaching and learning will be emphasised. It is hoped that participants in this study will be better equipped to succeed in their engineering studies as a result of developing a more robust set of core mathematical skills.

\section{CURRENT PROJECT STATUS}

This study stems from a pilot study carried out by Llorens [11]. Results from that pilot study showed that the active learner approach to online videos, where the students solve a problem and disseminate that solution to their peers via online videos, increases student engagement, encourages deeper thought, increases motivation and provides confidence for weaker students. The pilot experience showed that an increase in engagement with the subject matter resulted in higher rates of class attendance coupled with higher completion rates of assignment submissions.

This study aims to minimize the effect of diversity in prior knowledge in mathematics found in first year students as well as to increase engagement specifically for students who find themselves de-motivated and losing interest at a very early stage in their studies. A number of topics have been singled out for particular attention with students currently creating feedback videos in those areas. The online content consisting of the quizzes and feedback videos are being created simultaneously.

\section{Project Evaluation Plan}

Students will complete a maths diagnostic test at the beginning of the module and again after the study has completed. The results of the tests will be combined with prior information about the student (e.g. college entry data), the data obtained from the platform (e.g. how many tests were completed, scores for specific topics, feedback watched, feedback created, etc.) and the results of specific tests per-topic and per-student, focusing on the areas where the student showed weaknesses in the initial diagnostic test. A statistical analysis of the data together with a student survey and focus 
groups will provide both a quantitative and qualitative measurement of the level of success of the project and provide pointers to any future refinements, improvements and additions that could be integrated into the platform.

\section{PRELIMINARY RESULTS}

The initial, pre-intervention, capabilities of the students were measured using a standard maths diagnostic test [2] the results of which are displayed in Fig. 7. These results show the data skewed towards the lower values implying poor mathematical skills of the students.

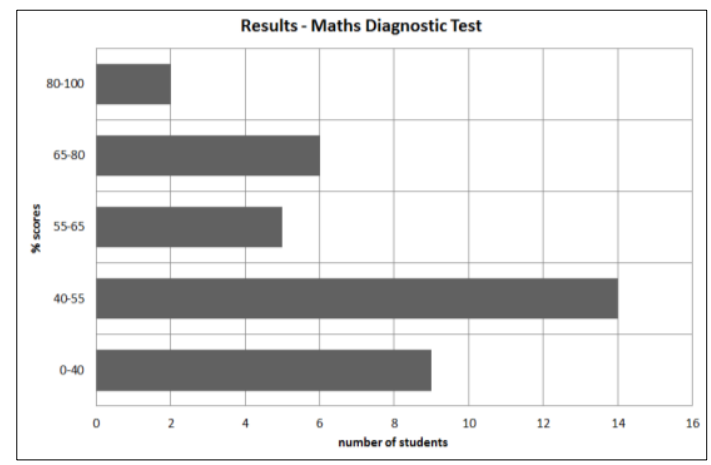

Figure 7. Results from the maths diagnostic test.

As part of this study a preliminary survey was conducted amongst the students who participated in the initial pilot. The first question posed was: 'Creating videos for the class was an enjoyable experience. Strongly Disagree-1, Disagree-2, Neither Agree/Disagree-3, Agree- 4, Strongly Agree- 5.' All the questions given to the students together with the results from the questionnaire are given in Table 1. The average response values are based on a five-point Likert scale:

TABLE I. PRELIMINARY SURVEY RESUlTS

\begin{tabular}{|l|c|}
\hline \multicolumn{1}{|c|}{ Question } & $\begin{array}{c}\text { Average } \\
\text { Response }\end{array}$ \\
\hline Creating videos for the class was an enjoyable experience. & 4.44 \\
\hline Creating videos was a useful experience. & 4.78 \\
\hline Creating videos was an interesting experience. & 4.33 \\
\hline I am glad I created a video. & 4.33 \\
\hline The video project was the most useful project in class. & 3.67 \\
\hline I would rather do a different project than the video project. & 1.89 \\
\hline Creating videos enhances learning content. & 4.67 \\
\hline Creating videos will enhance learning in future classes. & 4.44 \\
\hline I would recommend this project for future classes. & 4.78 \\
\hline
\end{tabular}

From these results it is evident that students who took part in the preliminary study embraced the technology and used it to enhance their learning experience.

\section{ProjeCted Status By THE CONFERENCE DATE}

By the conference date all students will have taken their modular exam. They will have had a number of topic-related videos available to them and will have completed a number of quizzes. An analysis of student performance and the impact of the student-created videos will have taken place. The use of feedback videos will be checked to see if there is a correlation with student learning outcomes which will be measured by their performance in quizzes and exams. Focus groups will have been carried out to determine the students' view of the benefits and limitations of the graphics tablets as an aid to their learning.

\section{FUTURE WORK}

The project can be continued for a number of years expanding the bank of questions, feedback videos and tools (e.g. using java applets, or mathematical applications such as Wiris, Geogebra or Maple). The platform will be continuously developed and will grow as new and improved resources created by both students and lecturers are added. The use of similar platforms for other technical subjects such as physics or chemistry will also be explored using the experiences and results from this project.

\section{ACKNOWLEDGMENTS}

Dr Brian Bowe Head of Learning Development, College of Engineering and the Built Environment, Dublin Institute of Technology, Bolton Street, Dublin 1, Ireland.

Staff of the Learning Teaching \& Technology Centre (LTTC), Dublin Institute of Technology, 14 Upper Mount Street, Dublin 2, Ireland.

\section{REFERENCES}

[1] S. Williamson, C. Hirst, P. Bishop, and T. Croft, "Supporting mathematics education in UK engineering departments," International Conference on Engineering Education, Valencia, Spain, July 2003.

[2] M. Carr, C. Fidalgo, E. B. de Almeida, J. R. Branco, and V. Santos, "Maths diagnostic testing in engineering: Dublin Institute of Technology and Coimbra Institute of Engineering," in Engineering Education (CISPEE), 2013, $1^{\text {st }}$ International Conference of the Portugese Society for (pp. 1-9). IEEE, 2013.

[3] C. Bovill, A. Cook-Sather, and P. Felten, "Students as co-creators of teaching approaches, course design, and curricula: implications for academic developers," International Journal for Academic Development, vol. 16:2, pp.133-145, June 2011.

[4] R. Anderson, L. McDowell, and B. Simon, "Use of classroom presenter in engineering courses," Frontiers in Education, 2005, FIE'05, Proceedings 35th Annual Conference, pp.T2G-13, IEEE, 2005.

[5] A. McCabe and U. O'Connor, "Student-centred learning: the role and responsibility of the lecturer," Teaching in Higher Education , 2013. http://dx.doi.org/10.1080/13562517.2013.860111

[6] M. Prince, "Does active learning work? A review of the research," Journal of Engineering Education, vol. 9:3, pp.223-231, 2004.

[7] H. Greene and C. Crespi, "The value of student created videos in the college classroom - an exploratory study in marketing and accounting." International Journal of Arts \& Sciences, vol.5:1, pp.273-283, 2012.

[8] C. McCartan, T. McNally, and J. Hermon, "An evaluation of active learning strategies applied to engineering mathematics," Proceeding of the 7th International CDIO Conference, pp.20-23, Technical University of Denmark, Copenhagen, June 2011.

[9] M. Fielding, "Radical collegiality: affirming teaching as an inclusive professional practice," The Australian Educational Researcher, vol. 26:2, pp.1-34, 1999.

[10] A. Carrillo, J. M. Cejudo, F. Dominquez, and E. Rodriguez, "Graphics tablet technology in second year thermal engineering teaching," Journal of Technology and Science Education, vol. 3:3, pp.102-112, 2013.

[11] M. Llorens, "Use of on-line video for mathematics peer instruction: apilot study," Proceedings $7^{\text {th }}$ International Technology, Education and Development Conference, pp.4411-4415, INTED2013, 2013. 